\title{
Ecomorphological variations and flow-induced phenotypic plasticity in Trichogaster fasciata using geometric and truss analysis
}

\author{
Farah Bano and M. Serajuddin* \\ Department of Zoology, University of Lucknow, Lucknow 226007 , India
}

Study of ecomorphological variations in fish of different habitats helps in understanding the diversification of body traits developed due to different environmental conditions. The morphological variations in subpopulations of Trichogaster fasciata induced by different habitats characterized by different environmental conditions have been studied. Overall, $86 \%$ and $92 \%$ of individuals were correctly classified using linear discriminant function analysis of truss and geometric morphometrics. The individuals from lotic habitat showed a more streamlined body, sloping head and inflated caudal peduncle than those of the lentic habitat which displayed deeper body, broader head and deflated caudal peduncle. Relative warps were used to quantify variations in the form of characteristic interpretation of body shape. The results from the present study help clarify the questions of morphological predictions in the sub-populations of this fish across different flow habitats and provide insights into phenotypic variations in the $T$. fasciata population.

Keywords: Geometric morphometrics, ecomorphological variation, phenotypic plasticity, Trichogaster fasciata, truss analysis.

ECOMORPHOLOGY is the study of ecological factors and their effects on the morphology of an individual, which includes the aspects of organismal biology and biomechanics that drive the morphological changes ${ }^{1,2}$ which helps in understanding the relationship between morphological traits and environmental factors ${ }^{3}$. Varieties of body shapes are produced in different populations of fish species because of variation in their maturation, growth and development due to the different environmental conditions ${ }^{4}$. Populations of the same individual of fish species originating from different geographical areas are morphologically different ${ }^{5}$. Phenotypic plasticity is the phenomenon which involves temporary morphological changes in response to the local environmental conditions during the early life stages of fish when the traits are more acquiescent to environmental influence ${ }^{6,7}$. In addition to phenotypic plasticity, the adaptations may be

\footnotetext{
*For correspondence. (e-mail: lu.fisheries@gmail.com)
}

genetically induced or may arise due to the combination of both ${ }^{8,9}$. Phenotypic plasticity or genetic modification ${ }^{10}$ is the result of shape variability in fish often attributed to the changes in biotic ${ }^{11}$ or abiotic ${ }^{12}$ factors. Apart from the mechanism of body transformations, the persistent endeavour by the individual to improve their fitness through natural selection may also be considered as the driving force behind these adaptations. The present study, does not test the cause or mechanisms behind these differences, but focuses on the morphological variations in body shape that occur in response to the different environmental conditions of various habitats.

The knowledge of sources about origin of body shape variation is fundamental and important for various types of biological research. However, the understandings of body shape variability to flow regimes remains limited for many freshwater fishes of India and researchers are often challenged to do so. Precise and accurate quantification of body shape of the fish is difficult and the methods employed for this range from traditional to modern. Morphometry of linear measurement (truss) using multivariate statistical analysis is traditionally used to quantify body shape in fishes ${ }^{13,14}$. Now, analysis of the geometric location of landmarks of the body is emerging as a powerful tool to quantify body shape variations to delineate the populations and in other areas of biological $\operatorname{research}^{14,15}$.

In the present study, the target fish species is Trichogaster fasciata, which is a commercially important freshwater ornamental fish. It is a benthopelagic fish ${ }^{16}$ widely known for its ornamental value as an aquarium species $^{17}$. It is known to occur in different types of water bodies, including freshwater pools, marshes, estuaries, ponds, large rivers, ditches and lakes in India and the neighbouring countries ${ }^{18}$. The variation in body shape of T. fasciata is possible as the fish inhabits different water bodies, i.e. lotic and lentic. Therefore, the present study is considered to be important towards exploration of the population structuring of $T$. fasciata collected from four different lotic and one lentic habitats of India. Begg and Waldman $^{19}$ suggested that complementary techniques are required to achieve greater resolution in the results. Therefore, two techniques (truss and geometric 
Table 1. Sampling details and descriptive data (mean \pm SE) of Trichogaster fasciata procured from lotic and lentic ecosystems of India

\begin{tabular}{|c|c|c|c|c|c|c|}
\hline \multirow[b]{2}{*}{ Sampling sites } & \multirow[b]{2}{*}{ Ecosystems } & \multirow[b]{2}{*}{ District } & \multirow[b]{2}{*}{ Geographical coordinates } & \multirow[b]{2}{*}{ Sample size } & \multicolumn{2}{|c|}{ Total length $(\mathrm{cm})$} \\
\hline & & & & & Range & Mean \pm SE \\
\hline Gomti & Lotic habitat & Lucknow & $26^{\circ} 56^{\prime} \mathrm{N}, 80^{\circ} 43^{\prime} \mathrm{E}$ & 30 & $5.7-8.2$ & $5.79 \pm 1.39$ \\
\hline Ganga & & Kanpur & $26^{\circ} 52^{\prime} \mathrm{N}, 80^{\circ} 52^{\prime} \mathrm{E}$ & 30 & $5.6-7.2$ & $5.45 \pm 0.91$ \\
\hline Ghaghara & & Faizabad & $27^{\circ} 17^{\prime} \mathrm{N}, 81^{\circ} 22^{\prime} \mathrm{E}$ & 30 & $6.7-9.4$ & $8.89 \pm 0.68$ \\
\hline Yamuna & & Delhi & $22^{\circ} 34^{\prime} \mathrm{N}, 88^{\circ} 22^{\prime} \mathrm{E}$ & 30 & $5.7-7.7$ & $6.34 \pm 1.37$ \\
\hline Bakhira Tal & Lentic Habitat & Sant Kabir Nagar & $26^{\circ} 53^{\prime} \mathrm{N}, 84^{\circ} 47^{\prime} \mathrm{E}$ & 30 & $4.5-7.1$ & $5.67 \pm 1.15$ \\
\hline
\end{tabular}

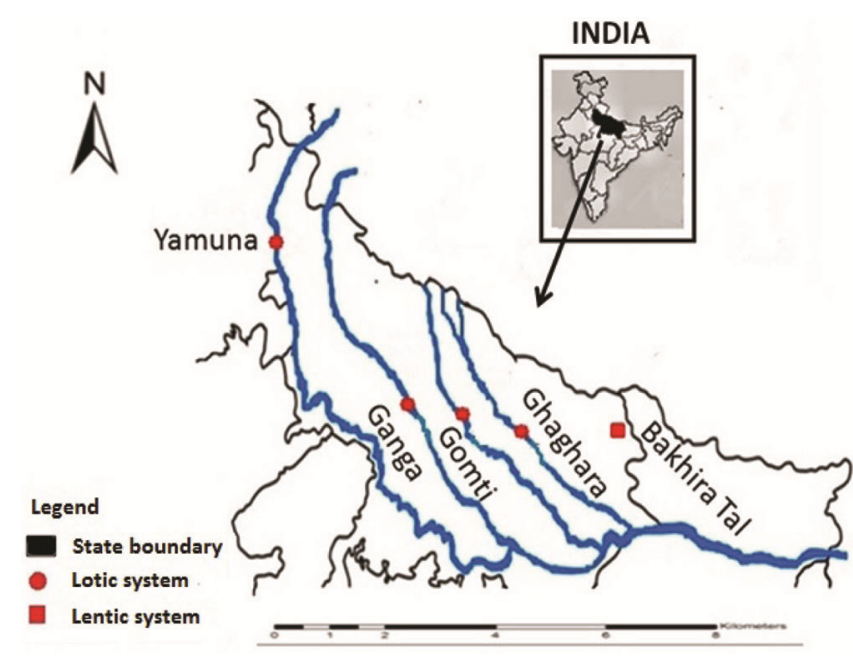

Figure 1. Map showing the sampling sites.

morphometrics) were used to illustrate and compare the ecomorphological variations among $T$. fasciata populations sampled from different habitats of India. Efforts were also made to compare the limitations and advantages of each of the methods used in the present study.

\section{Materials and methods}

\section{Sample collection}

Adult individuals of $T$. fasciata were procured using cast and drag nets (mesh size $=3-5 \mathrm{~cm}$ ) with the help of fisherman from five different habitats (four lotic and one lentic) situated in different parts of India. The lotic habitats include four rivers (Gomti in the Lucknow region, Ganga at Kanpur, Ghaghara at Faizabad and Yamuna at Delhi), and one lentic (Bakhira Tal at Sant Kabir Nagar). Table 1 and Figure 1 provide the details. The fish samples were brought to the laboratory for morphometric study. Each fish was placed on the truss paper along a straight line and the image of the left side of the fish was captured using a digital camera (Nikon 16.0 mega pixel). Ten landmarks were chosen using the software tpsDig (2.09) (ref. 20; Figure 2) and transformed into cartesian coordinates.

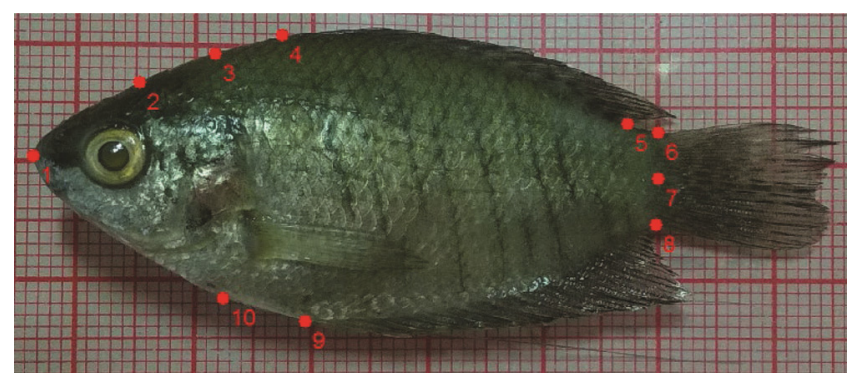

Figure 2. Landmarks shown on the fish body. They include: (1) snout tip, (2) dorsal edge of head perpendicular to the end of the eye; (3) dorsal edge of head perpendicular to the opercular bone, (4) anterior origin of the dorsal fin, (5) posterior insertion of the dorsal fin, (6) upper origin of the caudal fin, (7) middle of the caudal fin, (8) lower insertion of the caudal fin, (9) the anterior origin of the anal fin and (10) the anterior origin of the pelvic fin.

\section{Truss analysis}

The truss analysis was carried out by interconnecting the landmarks. Prior to data analysis, the data were $\log _{10}$ transformed and standardized using the allometric method as described by Elliott et al. ${ }^{21}$ for interpretation of shape variation independent of the fish size.

\section{Geometric morphometrics}

Geometric morphometrics was carried out on the cartesian coordinates of landmarks on each specimen, followed by Procrustes superimposition to standardize the landmark coordinates of each specimen to unit centroid size, which removes information about location, size and orientation. The coordinates of all aligned specimens were subjected to deformation grids, the relative warp (RW) analysis ${ }^{22}$ to quantify and graphically portray the patterns of variations among five populations of T. fasciata.

\section{Data analysis}

The data were tested for normality using the Shapiro Wilk test and Levene's test. MANOVA was carried out to test the significance of differences among the samples. Linear stepwise discriminant function analysis (LDFA) 
Table 2. Canonical correlation analysis among the five populations of $T$. fasciata using truss analysis and geometric morpometrics

\begin{tabular}{lcccc}
\hline Function & Eigen value & Percentage of variance & Cumulative (\%) & Canonical correlation \\
\hline Truss analysis & & & & 0.861 \\
DF1 & 2.870 & 54.7 & 54.7 & 0.798 \\
DF2 & 1.749 & 33.3 & 88.0 & 0.620 \\
DF3 & 0.625 & 12.0 & 100 & 0.910 \\
& & & & 0.861 \\
Geometric morphometrics & & & 60.6 & 0.606 \\
DF1 & 4.847 & 60.6 & 84.2 & 0.454 \\
DF2 & 2.878 & 23.6 & 97.0 & 100.0 \\
DF3 & 0.581 & 12.8 & & \\
DF4 & 0.260 & 3.0 & & \\
\hline
\end{tabular}

Table 3. Wilk's lambda test of discriminant function analysis among five populations of $T$. fasciata using truss analysis and geometric morphometrics

\begin{tabular}{lcccc}
\hline Method & Test of functions & Wilk's lambda & df & $P$ \\
\hline Truss analysis & 1 through 3 & 0.029 & 20 & 0.000 \\
& 2 through 3 & 0.141 & 12 & 0.000 \\
Geometric morphometrics & 3 & 0.666 & 6 & 0.000 \\
& 1 through 4 & 0.022 & 32 & 0.000 \\
& 2 through 4 & 0.129 & 21 & 0.000 \\
& 3 through 4 & 0.502 & 12 & 0.000 \\
\hline df, degrees of freedom; $P$, Significance value. & 4 & 0.784 & 5 & 0.000 \\
\hline
\end{tabular}

was used to calculate the percentage of correctly classified individuals (PCC), and Wilk's lambda was used to compare the dissimilarity between groups. Statistical analysis was carried out using SPSS version 16.0 and the paleontological software, PAST version 3.12. The data were represented as mean $\pm \mathrm{SE}$ and probability level was set as less than 0.05 .

\section{Results}

\section{Truss morphometrics}

Truss morphometric measurements differed significantly among the five populations (MANOVA, $P<0.001$ ). LDFA resulted into the generation of three discriminant functions (DFs), namely DF1 (54.7\%; Wilk's lamb$\mathrm{da}=0.029)$, DF2 $(33.3 \%$; Wilk's lambda $=0.141)$ and DF3 $(12 \%$; Wilk's lambda $=0.666)$, which indicated significant differences at the level of $P<0.001$ in the morphometric characters. Tables 2 and 3 provide the details. The morphometric traits such as $3-4,3-7,2-8,3-8,1-$ $10,1-2$ and $6-7,4-7,4-8,4-6,5-7$ were highly correlated to DF1 and DF2 respectively. Overall, $86 \%$ of original grouped cases were correctly classified using LDFA (Table 4). The scatter plot of DF1 and DF2 showed that the individuals from lotic habitat overlapped and were found to be closer to each other, whereas the individuals from lentic habitat were quite distinct (Figure $3 a$ ).

\section{Geometric morphometrics}

Geometric morphometrics revealed significant differences among the five populations of $T$. fasciata (MANOVA, $P<0.001)$. In LDFA, four DFs were generated, viz. DF1 $(60.6$; Wilk's lambda $=0.022)$, DF2 (23.6; Wilk's lamb$\mathrm{da}=0.129)$, DF3 (12.8; Wilk's lambda $=0.502)$ and DF4 (3.0; Wilk's lambda $=0.784)$, which indicated significant differences $(P<0.001)$ in the morphometric characters (Tables 2 and 3). The landmarks that contributed to DF1 and DF2 were 2, 5, 4, 6, 3, 1 and 7, 8, 9 and 10 respectively. A classification matrix indicated that overall $92 \%$ of individuals were correctly classified into their original group (Table 4). The scatter plot of DFs (1 and 2) indicated the existence of five distinct populations of $T$. fasciata (Figure $3 \mathrm{~b}$ ). In the present study, relative warps showed that significant differences were contributed by head region, body depth and caudal peduncle (Figure 4).

\section{Discussion}

The integrative approach of truss and geometric morphometrics revealed significant ecomorphological variations in the body shape of $T$. fasciata. The specific traits which produced shape variation in different populations of $T$. fasciata were body depth, caudal peduncle and head region. Populations from the lotic ecosystems (Gomti, 
Table 4. Per cent values of cross-validated discriminant analysis in morphometrics measurements of $T$. fasciata using truss analysis and geometric morphometrics

\begin{tabular}{|c|c|c|c|c|c|c|}
\hline \multirow[b]{2}{*}{ Population percentage $(\%)$} & \multicolumn{5}{|c|}{ Predicted group membership } & \multirow[b]{2}{*}{ Total } \\
\hline & Gomti & Ganga & Ghaghara & Yamuna & Bakhira Tal & \\
\hline \multicolumn{7}{|l|}{ Truss analysis } \\
\hline Gomti & $73.3(22)$ & $20(6)$ & $0(0)$ & $0(0)$ & $6.7(2)$ & 100 \\
\hline Ganga & $10(3)$ & $90(27)$ & $0(0)$ & $0.0(0)$ & $0(0)$ & 100 \\
\hline Ghaghara & $0(0)$ & $6.7(2)$ & $73.3(22)$ & $3.3(1)$ & $16.7(5)$ & 100 \\
\hline Yamuna & $0(0)$ & $0(0)$ & $3.3(1)$ & $86.7(26)$ & $10(3)$ & 100 \\
\hline Bakhira Tal & $6.7(2)$ & $13.3(4)$ & $10(3)$ & $0(0)$ & $70(21)$ & 100 \\
\hline \multicolumn{7}{|c|}{$86 \%$ of original grouped cases correctly classified } \\
\hline \multicolumn{7}{|l|}{ Geometric morphometrics } \\
\hline Gomti & $90(27)$ & $3.3(1)$ & $0(0)$ & $0(0)$ & $6.7(2)$ & 100 \\
\hline Ganga & $3.3(1)$ & $93.3(28)$ & $0(0)$ & $0(0)$ & $3.3(1)$ & 100 \\
\hline Ghaghara & $0(0)$ & $3.3(1)$ & $93.3(28)$ & $3.3(1)$ & $0(0)$ & 100 \\
\hline Yamuna & $0(0)$ & $0(0)$ & $0(0)$ & $96.7(29)$ & $3.3(1)$ & 100 \\
\hline Bakhira Tal & $6.7(2)$ & $6.7(2)$ & $0(0)$ & $20(6)$ & $66.7(20)$ & 100 \\
\hline \multicolumn{7}{|c|}{$92 \%$ of original grouped cases correctly classified } \\
\hline
\end{tabular}

The corresponding numbers of individuals are given within parentheses.
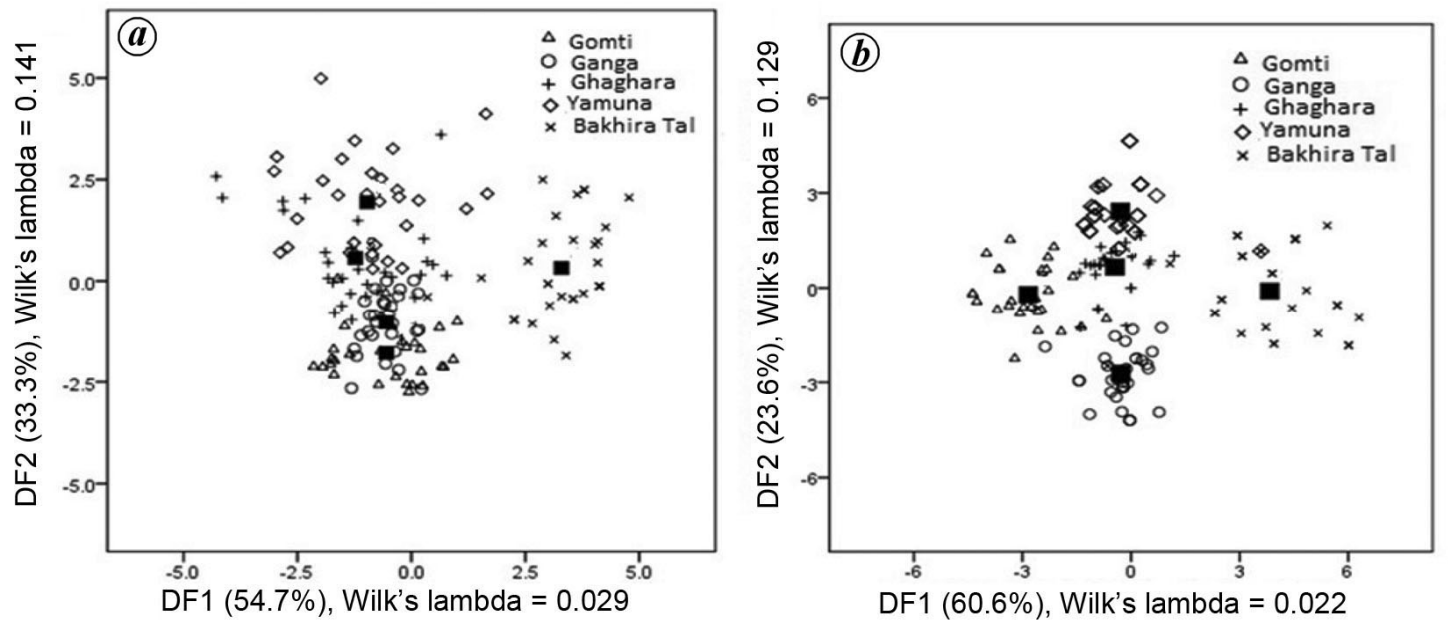

Figure 3. Discriminant function analysis plot between DF1 and DF2. (a) Truss analysis and (b) geometric morphometrics.

Ganga, Ghaghara and Yamuna) exhibited similarities in possessing a more streamlined body (lower body depth) and inflated caudal peduncle than those from the lentic ecosystems (Bakhira Tal), where traits such as deeper body and deflated caudal peduncle were noted. Several researchers have reported similar results in different fish species all over the world ${ }^{23-25}$. The traits of lotic and lentic individuals, reported in the present study, were due to adaptations of the fish in high and low water current present in riverine and stagnant water body respectively. The deeper body shape increases the drag exerted on the body of the fish in moving water, requiring more energy to navigate through or remain stable ${ }^{26,27}$. However, when compared with more streamlined fishes, it reduces the drag and enhances the swimming speed and ability ${ }^{28,29}$. In the present study, the fish population in lotic habitats had elongated caudal peduncle compared to those of the lentic populations. An elongated and more robust caudal peduncle improves the ability to sustained swimming and the energy lost due to recoiling is reduced through maximizing the thrust $\mathrm{t}^{28,30}$. The sloping head of $T$. fasciata in the fish of lotic ecosystems is designated to help in water movement over the head, improving its ability to forage ${ }^{29}$ and avoid predation ${ }^{31}$. Fish living in lentic habitats do not adapt to flow, rather they are supposed to respond to different environmental pressures ${ }^{29}$, resulting in body shape differences. The morphological variations in the fish (body depth, head shape and caudal peduncle size and shape) are likely to be environmentally driven, but the changes are considered to have been gradually developed in several generations at the population scale in the response to the environmental gradients ${ }^{32,33}$.

CURRENT SCIENCE, VOL. 120, NO. 3, 10 FEBRUARY 2021 


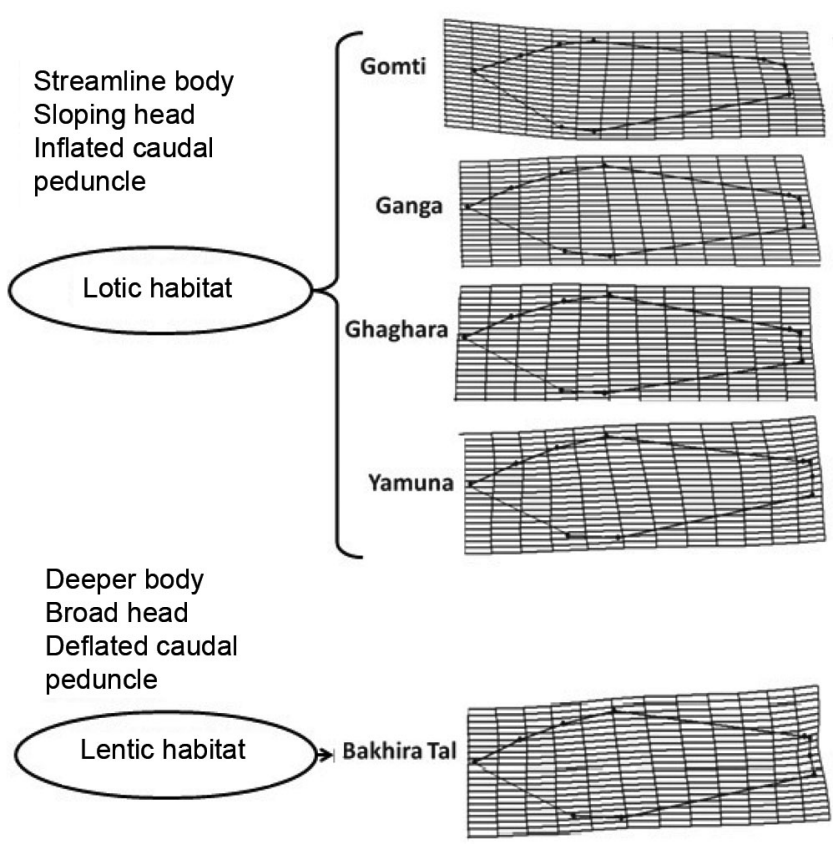

Figure 4. Relative warps of five distinct populations of Trichogaster fasciata from lotic and lentic ecosystems of India.

The two morphometric methods, truss and geometric morphometrics, are considered to be advanced and well organized, which include coverage of the entire form with improved statistical and standardization power using multivariate shape variability over univariate measurements ${ }^{13}$. An important limitation of truss analyses is that it provides variability in the shape of objects that are particularly dependent on distance-based measures of morphological characters (size differences) and on axes (e.g. principal components) that do not provide direct representation of the object making biological interpretation difficult for researchers ${ }^{34,35}$. Nevertheless, the truss analysis is widely used to assess the degree of differentiation because it is related to the functional morphology of the individual population of the fish ${ }^{36}$. In comparison to truss analysis, geometric morphometrics provides shapebased measures of morphological characters ${ }^{13,37}$. Geometric morphometrics overcomes the limitations and increases the discriminating power due to vigorous measures of the variation among objects in Procrustes distance ${ }^{15}$ and characterization of multivariate shape variability, especially when size differences among specimens are small $^{22,35}$. In the present study, geometric methods of landmark coordinates permit characterization of shape variation among the different populations of $T$. fasciata by means of relative warps, which were visual representations of shape variations (Figure 4). Similarly, other studies have reported that geometric morphometric is a powerful, more robust tool and allows for better visualization of shape differences in fishes ${ }^{38,39}$. However, the common drawback of geometric morphometrics is that it cannot be used to interpret the functional morphology of fish $^{40}$. Additionally, Bhagat et al. ${ }^{36}$ pointed out that comparison of the two methods shows only a minor deviation in the final results. Similarly, slight variations were observed in the morphometric parameters of body shape in T. fasciata.

\section{Conclusion}

Ecomorphological variations slowly develop in subpopulations of fish during early stages because of different habitats characterized by different environmental conditions. However, further studies are needed from combined field assays of morphological variations along with laboratory experiments and genetic analyses to authenticate the results.

1. Liem, K. F., Toward a new morphology: pluralism in research and education. Am. Zool., 1991, 31, 759-767.

2. Wainwright, P. C., Ecomorphology: experimental functional anatomy for ecological problems. Integr. Comp. Biol., 1991, 31, 680-693.

3. Shukla, R. and Bhat, A., Morphological divergences and ecological correlates among wild populations of zebrafish (Danio rerio). Environ. Biol. Fish., 2017, 100, 251-264.

4. Cadrin, S. X., Advances in morphometric identification of fishery stocks. Rev. Fish Biol. Fish., 2000, 10, 91-112.

5. Paugy, D. and Lévêque, C., Taxinomie et systématique. In Les Poissons des Eaux Continentales Africaines, Diversité, Écologie et Utilisation par L'homme (eds Lévêque, C. and Paugy, D.), IRD, Paris, France, 1999, pp. 97-119.

6. Wimberger, P. H., Plasticity of fish body shape, the effects of diet, development, family and age in two species of Geophagus (Pisces: C'ichlidae). Biol. J. Linn. Soc., 1992, 45, 197-218.

7. Pinheiro, A., Teixeira, C. M., Rego, A. L., Marques, J. F. and Cabral, H. N., Genetic and morphological variation of Solea lascaris (Risso 1810) along the Portuguese coast. Fish Res., 2005, 73, 67-78.

8. Proulx, R. and Magnan, P., Contribution of phenotypic plasticity and heredity to the trophic polymorphism of lacustrine brook charr (Salvelinus fontinalis M.). Evol. Ecol. Res., 2004, 6, 503-522.

9. Svanbäck, R. and Eklöv, P., Genetic variation and phenotypic plasticity: causes of morphological and dietary variation in Eurasian perch. Evol. Ecol. Res., 2006, 8,37-34.

10. Lande, R. and Shannon, S., The role of genetic variation in adaptation and population persistence in a changing environment. Evolution, 1996, 50, 434-437.

11. Agrawal, A. A., Phenotypic plasticity in the interaction and evolution of species. Science, 2001, 294, 321-326.

12. Fulton, C. J., Binning, S. A., Wainwright, P. C. and Bellwood, D. R., Wave-induced abiotic stress shapes phenotypic diversity in a coral reef fish across a geographical cline. Coral. Reefs, 2013, 32, 685-689.

13. Strauss, R. E. and Bookstein, F. L., The truss: body form reconstruction in morphometrics. Syst. Zool., 1982, 31, 113-135.

14. Adams, D. C., Rohlf, F. J. and Slice, D. E., Geometric morphometrics: ten years of progress following the 'revolution'. Ital. J. Zool., 2003, 71, 5-16.

15. Bookstein, F. L., Combining the tools of geometric morphometrics. In Advances in Morphometrics (eds Marcus, L. F. et al.), NATO ASI Series A: Life Sciences, Plenum Publishing, New York, USA, 1996, vol. 284, pp. 131-151. 
16. Menon, A. G. K., Check list - fresh water fishes of India. Zoological Survey of India Occasional Paper 1999, No. 175, p. 366.

17. Goodwin, D., The Practical Aquarium Fish Handbook, Sterling Publishing Company, New York, USA, 2003.

18. Talwar, P. K. and Jhingran, A. G., Inland Fishes of India and Adjacent Countries, Rotterdam, A.A. Balkema, The Netherlands, 1991.

19. Begg, G. A. and Waldman, J. R., An holistic approach to fish stock identification. Fish. Res., 1999, 43, 35-44.

20. Rohlf, F. J., tpsDig 2.10, Department of Ecology and Evolution, State University of New York, Stony Brook, NY, USA, 2006.

21. Elliott, N. G., Haskard, K. and Koslow, J. A., Morphometric analysis of orange roughly (Hoplostethus atianticus) off the continental slope of Southern Australia. J. Fish Biol., 1995, 46, 202-220.

22. Bookstein, F. L., Morphometric Tools for Landmark Data, Cambridge University Press, Cambridge, UK, 1991.

23. Collin, H. and Fumagalli, L., Evidence for morphological and adaptive genetic divergence between lake and stream habitats in European minnows (Phoxinus phoxinus, Cyprinidae). Mol. Ecol., 2011, 20, 4490-4502.

24. Meyers, P. J. and Belk, M. C., Shape variation in a benthic stream fish across flow regimes. Hydrobiologia, 2014, 738, 147-154.

25. Cureton, J. C. and Broughton, R. E., Rapid morphological divergence of a stream fish in response to changes in water flow. Biol. Lett., 2014, 10, 20140352.

26. Bronmark, C. and Miner, J. G., Predator-induced phenotypical change in body morphology in crucian carp. Science, 1992, 258, 1348-1350.

27. Matthews, W. J., Patterns in Freshwater Fish Ecology, Chapman and Hall, New York, USA, 1998.

28. Blake, R. W., Law, T. C., Chan, K. H. S. and Li, J. F. Z., Comparison of the prolonged swimming performances of closely related, morphologically distinct three-spined sticklebacks Gasterosteus spp. J. Fish. Biol., 2005, 67, 834-848.

29. Ehlinger, T. J. and Wilson, D. S., Complex foraging polymorphism in bluegill sunfish. Proc. Natl. Acad. Sci. USA, 1988, 85, 1878-1882.

30. Brinsmead, J. and Fox, M. G., Morphological variation between lake-and stream-saima rock bass and pumpkinseed populations. J. Fish Biol., 2002, 61, 1619-1638.

31. Webb, P. W., Form and function in fish swimming. Sci. Am., 1984, 251, 72-82.

32. Langerhans, R. B., Predictability of phenotypic differentiation across flow regimes in fishes. Integr. Comp. Biol., 2008, 48, 750768 .
33. Rivera, G., Ecomorphological variation in shell shape of the freshwater turtle Pseudemys concinna inhabiting different aquatic flow regimes. Integr. Comp. Biol., 2008, 48, 769-787.

34. Rohlf, F. J., Loy, A. and Corti, M., Morphometric analysis of Old World Talpidae (Mammalia, Insectivora) using partial warp scores. Syst. Biol., 1996, 45, 344-362.

35. Yaroch, L. A., Shape analysis using the thin-plate spline: neanderthal cranial shape as an example. Am. J. Phys. Anthropol., 1996, 39, 43-89.

36. Bhagat, Y., Fox, M. J. and Ferreira, M. T., Morphological diversification in introduced pumpkinseed (Lepomis gibbosus): assessing truss-based and geometric morphometric approaches. Fundam. Appl. Limnol., 2011, 178, 341-351.

37. Webster, M. and Sheets, H. D., A practical introduction to landmark-based geometric morphometrics. Palaeontol. Soc. Pap., 2010, 16, 163-188.

38. Parsons, K. J., Robinsona, B. W. and Hrbek, T., Getting into shape: an empirical comparison of traditional truss-based morphometric methods with a newer geometric method applied to New World cichlids. Environ. Biol. Fish, 2003, 67, 417-431.

39. Maderbacher, M., Bauer, C., Herler, J., Postl, L., Makasa, L. and Sturmbauer, C., Assessment of traditional versus geometric morphometrics for discriminating populations of the Tropheus moorii species complex (Teleostei: Cichlidae), a Lake Tanganyika model for allopatric speciation. J. Zool. Syst. Evol. Res., 2008, 46, 153161.

40. Ruber, L. and Adams, D. C., Evolutionary convergence of body shape and trophic morphology in cichlids from Lake Tanganyika. J. Evol. Biol., 2001, 14, 325-332.

ACKNOWLEDGEMENTS. We thank the Head, Department of Zoology, University of Lucknow for providing the necessary facilities and administrative support. F.B. thanks the University Grants Commission, New Delhi for a senior research fellowship (Ref No-19/06/2016(i) EU-V).

Received 22 September 2019; revised accepted 23 September 2020

doi: $10.18520 / \mathrm{cs} / \mathrm{v} 120 / \mathrm{i} 3 / 547-552$ 